\title{
Bacterial Brain Abscess Early Treated with Oral Antibiotics in A Case Series of Immunocompetent Adult Patients: Could This Be A Feasible Therapy?
}

\author{
Nicola Dentale ( $\square$ nicola.dentale@aosp.bo.it) \\ IRCCS Policlinico S.Orsola Malpighi - Deprtment of Medical and Surgical Science - Bologna University \\ Simona Coladonato \\ IRCCS Policlinico S.Orsola -Malpighi -Department of Medical and Surgical Science - Bologna University \\ Irene Zaghi \\ IRCCS Policlinico S.Orsola -Malpighi -Department of Medical and Surgical Science - Bologna University \\ Luca Spinardi \\ IRCCS Policlinico S.Orsola-Malpighi Department of Medical and Surgical Science - Bologna University \\ Sara Rosa Maria De Martino \\ IRCCS Poloclinico S.Orsola-Malpighi Department of Medical and Surgical Science - Bologna Universitu \\ Pierluigi Viale \\ IRCCS Policlinico S. Orsola Malpighi - Department of Medical and Surgical Science - Bologna University
}

\section{Research Article}

Keywords: Brain abscess, Oral Antibiotics, Bacterial Infections, Immunocompetent patients

Posted Date: February 28th, 2022

DOI: https://doi.org/10.21203/rs.3.rs-297016/v1

License: (c) (i) This work is licensed under a Creative Commons Attribution 4.0 International License. Read Full License 


\section{Abstract \\ BACKGROUND.}

We report the preliminary observation of community acquired brain abscess in immunocompetent adult patients early treated with high penetrating oral antibiotics, even without microbiological isolation, that showed good outcome.

\section{METHODS.}

A retrospective analysis of eight patients being managed for brain abscess who underwent early oral antimicrobial therapy is reported. Data collected of age, sex, co-morbidity, risk factors, diameter of the abscess, microbiological findings, management of therapy, focusing on its early shift to oral regimen and outcome after one year of follow-up.

\section{RESULTS.}

Two of eight patients, with a mean age of 59,3 years, required neurosurgery, in 3 case we found positive microbiological samples. The medium length from initial i.v. therapy to per os regimen was 7,7 and the medial length of the complete course of therapy was 58 days. Most of them received the same empiric antimicrobial therapy with levofloxacin and linezolid, because of their high oral bioavailability and optimal penetration into brain barrier. All the patients had clinical improvement and showed no signs of persistent cerebral abscess at one year of follow-up.

\section{CONCLUSIONS.}

Cerebral abscess is a significant cause of morbidity and mortality, nevertheless, in selected cases, it can be treated with antimicrobial therapy per os, even in case of negative microbiological samples. Oral antimicrobial therapy could be non inferior to intravenous antibiotic therapy, moreover it has advantages reducing time of hospital stay and improving quality of life and patient compliance to long period of antimicrobial treatment.

\section{Introduction}

Brain abscess is an infection of the brain, in most cases due to bacteria, especially when community acquired in immunocompetent adult patients [1-6], fortunately with low incidence. It is a focal infection that begins with an area of cerebritis. Bacteria reach the brain through contiguous area (ear, sinus, adjacent cranial trauma or neurosurgery) or hematogenous dissemination[1-6]. It requires many specialists for a correct management[5-7] because the best option is antibmicrobial therapy associated with source control, when feasible. Most of the times brain abscess are polymicrobial and a de-escalation of antimicrobial therapy can be hard. Treatment should cover the most frequent causative agents: oral streptococci (including milleri group), meticillin-susceptible staphylococci, anaerobes, and Enterobacteriaceae. At the moment for brain bacterial abscess in immunocompetent patients it is suggested a combination of third-generation cephalosporin and metronidazole administred through intravenous route for at least 6-week[8]. It is controversial for how long intravenous antimicrobial therapy is mandatory. We report some cases with good outcome, early treated with high penetration regimen of oral antibiotics, even without microbiological isolation.

Prospective studies are needed to establish if selected patient can beneficiate of early per os antimicrobial therapy.

\section{Patients And Methods}

Data on patients diagnosed with brain abscess were collected retrospectively starting from 2015 in Sant'Orsola Malpighi Teaching Hospital in Bologna. On a total of 45 cerebral infectious pathologies, we eliminated those regarding immune-compromised patients and meningitides; we focused, described and discussed in detail the characteristics of only the immunocompetent patients (3,6\%): Charlson score, type and localization of the lesion, surgical and antimicrobial treatment (type and lenght), Table 1. All patients underwent neurosurgical consult after neuroradiological imaging was performed. In most case no etiologic diagnosis was made due to small diameter of cerebral lesions (not susceptible for brain biopsy), or negative microbiological culture. Antimicrobial regimen was chosen on the suspect of bacterial-origin brain abscess in the immunocompetent host and on PK-PD drug parameters. After the usual initial intravenous approach, patients showing good clinical conditions were rapidly shifted to oral route. It is known that oral antibiotic therapy is associated with a shorter length of hospitalization, fewer side effects and good compliance, in accordance with recently published data regarding other kind of severe infections such as Endocarditis and Osteomyelitis[2, 3, 4]. Six- eight weeks of intravenous antimicrobial therapy in bacterial brain abscess could be successfully replaced by oral antibiotics with similar duration but shorter hospitalization[4, 16]. All patients were early discharged, early shifted to oral regimen and monitored at followed-up by ambulatory clinical and radiological evaluation at 1,3,6,12 months. Therapy Drug Monitoring (TDM) were performed to early recognize and limit adverse antimicrobial effect. 
Table 1

\begin{tabular}{|c|c|c|c|c|c|c|c|c|}
\hline Patient & 1 & 2 & 3 & 4 & 5 & 6 & 7 & 8 \\
\hline $\begin{array}{l}\text { Age and } \\
\text { (sex) }\end{array}$ & $18(m)$ & $47(f)$ & $52(\mathrm{~m})$ & $71(\mathrm{~m})$ & $59(\mathrm{~m})$ & $83(f)$ & $86(f)$ & $59(\mathrm{~m})$ \\
\hline $\begin{array}{l}\text { Charlson } \\
\text { index }\end{array}$ & 0 & 0 & 1 & 4 & 1 & 4 & 4 & 1 \\
\hline $\begin{array}{l}\text { Risk } \\
\text { factors }\end{array}$ & Not found & $\begin{array}{l}\text { Parodontal } \\
\text { disease }\end{array}$ & Not found & Splenectomy & Dental care & Not found & $\begin{array}{l}\text { Paragangl. } \\
\text { of ear }\end{array}$ & Not found \\
\hline Symptoms & seizures & $\begin{array}{l}\text { headache, } \\
\text { altered mental } \\
\text { status }\end{array}$ & $\begin{array}{l}\text { headache, } \\
\text { fever }\end{array}$ & $\begin{array}{l}\text { fever, } \\
\text { vomiting, } \\
\text { aphasia }\end{array}$ & $\begin{array}{l}\text { headache, } \\
\text { diplopia }\end{array}$ & confusion & $\begin{array}{l}\text { fever, } \\
\text { earache }\end{array}$ & $\begin{array}{l}\text { right arm } \\
\text { parestesia, } \\
\text { fever }\end{array}$ \\
\hline $\begin{array}{l}\text { Diameter } \\
\text { (cm) }\end{array}$ & 1.0 & 2.0 & 3.5 & 2.1 & 1.6 & 0.1 & 2.4 & 2.5 \\
\hline Site & parietal & thalam & tempor & parietal & bulb & pons & tempor & rolandic \\
\hline Surgery & No & Yes & Yes & No & No & No & No & No \\
\hline Isolate & No & $\begin{array}{l}\text { Streptococcus } \\
\text { intermedius }\end{array}$ & $\begin{array}{l}\text { Streptococcus } \\
\text { intermedius }\end{array}$ & $\begin{array}{l}\text { Streptococcus } \\
\text { pneumoniae }\end{array}$ & No & No & No & No \\
\hline $\begin{array}{l}\text { Initial i.v. } \\
\text { therapy } \\
\text { (days) }\end{array}$ & 9 & 0 & 16 & 14 & 0 & 0 & 9 & 14 \\
\hline $\begin{array}{l}\text { Antibiotic } \\
\text { (first line) }\end{array}$ & $\begin{array}{l}\text { levofloxacin } \\
\text { +linezolid }\end{array}$ & linezolid & $\begin{array}{l}\text { linezolid + } \\
\text { meropenem }\end{array}$ & $\begin{array}{l}\text { levofloxacin } \\
\text { +ceftriaxon }\end{array}$ & $\begin{array}{l}\text { levofloxacin } \\
\text { +linezolid }\end{array}$ & $\begin{array}{l}\text { levofloxacin } \\
\text { + linezolid }\end{array}$ & $\begin{array}{l}\text { meropenem } \\
+ \\
\text { clindamicin }\end{array}$ & $\begin{array}{l}\text { levofloxacin } \\
\text { +linezolid }\end{array}$ \\
\hline $\begin{array}{l}\text { Switch to } \\
\text { second line } \\
\text { therapy }\end{array}$ & No & No & $\begin{array}{l}\text { levofloxacin } \\
\text { +linezolid }\end{array}$ & levofloxacin & linezolid & levofloxacin & $\begin{array}{l}\text { levofloxacin } \\
+ \text { linezolid }\end{array}$ & linezolid \\
\hline $\begin{array}{l}\text { Adverse } \\
\text { effects }\end{array}$ & No & No & $\begin{array}{l}\text { GI } \\
\text { Disturbances }\end{array}$ & No & Anemia & Anemia & Anemia & $\begin{array}{l}\text { delayed } \\
\text { rupture of } \\
\text { Achille's } \\
\text { tendon }\end{array}$ \\
\hline $\begin{array}{l}\text { Total } \\
\text { duration } \\
\text { (days) }\end{array}$ & 61 & 48 & 40 & 46 & 60 & 65 & 65 & 80 \\
\hline $\begin{array}{l}\text { Persistence } \\
\text { of } \\
\text { symptoms } \\
\text { at } 6 \text { - month } \\
\text { follow up }\end{array}$ & No* & No & No & No & No* & No & No & No \\
\hline $\begin{array}{l}\text { Persistence } \\
\text { of } \\
\text { radiological } \\
\text { lesion at 6- } \\
\text { month } \\
\text { follow- up }\end{array}$ & $\mathrm{No}^{*}$ & No & No & No & $\begin{array}{l}\text { residual } \\
\text { lesion* }\end{array}$ & No & $\begin{array}{l}\text { residual } \\
\text { lesion }\end{array}$ & $\begin{array}{l}\text { residual } \\
\text { lesion }\end{array}$ \\
\hline
\end{tabular}

\section{Clinical features of cases reported}

Patient 1. A 18 year-old man, in good health, presented a single episode of seizure with generalization. A brain MR showed $1 \mathrm{~cm}$ abscess in left posterior cingulate gyrus with concomitant thin subdural flogistic effusion of about $3 \mathrm{~mm}$. Intravenous regimen with vancomicyn, meropenem and metronidazole was started, the patient was transferred to our hospital three days later and a shift to oral regimen with levofloxacin and linezolid was decided, because of his stable clinical conditions and ability to oral intake. Liquor and blood culture were negative. A new brain RM was performed after 9 days from the previous one and showed the persistence of the abscess lesion (Fig. 1-A) with minimal increase of the perilesional edema and left interhemispheric subdural empyema. The patient was discharged seven day later. Brain imaging were performed that showed a reduction of size of the lesion after two weeks of treatment with oral antibiotics (Fig. $1-B$ ). RM of the brain showed a complete resolution of the same lesion after 8 weeks of oral antimicrobial treatment (Fig. $1-\mathrm{C}$ ). Patient 2. A 47 year old woman with a three day history of vomiting and headache underwent a brain CT scan and an MRI that showed an expansive lesion of left thalamus associated with hydrocephalus (Fig. 2-A), so a 
ventricular external drainage was performed. Blood culture was negative, the CFS was indicative of meninigitis, Streptococcus intermedius was found at colture and linezolid was started. A panoramic dental-scan was evocative for a chronic parodontal disease.

After two weeks of treatment and ventricular catheter removal, the brain CT scan showed a volumetric reduction of the thalamic abscess (Fig. 2-B) after one month of therapy. The follow-up brain MR at 1 month showed a complete resolution of the abscess (Fig. 2-C); she was asymptomatic and the treatment was stopped. Patient 3. A 52 year old man, presented headache and fever with slighty increase of proteine C reactive. A MR scan defined an abscess in the right temporal lobe and a small fronto-temporal subdural empyema (Fig. 3-A). Treatment with ceftriaxone plus vancomycin was started, there were no surgical indications because of the small size of lesion (diameter $1,5 \times 1 \mathrm{~cm}$ ). Unfortunately seizures occurred three day later and the brain CT scan showed an increase of temporal lesion up to $3.5 \mathrm{~cm}$. Phenitoyn, meropenem plus linezolid were started.

The patient underwent a fronto-parietal craniotomy to drain the abscess. Cultural intra-operatory sample was positive for Streptococcus intermedius. Levofloxacin was added instead of meropenem. Two weeks later a new brain MR documented a complete resolution of the abscess with a sterile post-surgical subdural collection (Fig. 3-B), so antibiotics were discontinued after 40 days. A follow-up imaging after two months revealed complete resolution of the post-surgical changes (Fig. 3-C). Patient 4. A 71 year old man presented fever, vomiting, aphasia and altered mental status. Nine month before he underwent to vascular surgery because of an aneurysm of abdominal aorta with aortic replacement and splenectomy. After a negative brain CT scan, a lumbar puncture was indicative of bacterial meningitis so ceftriaxone, levofloxacin and dexametasone were immediately started. Pneumococcal meningitis was microbiologically confirmed within 6 hours. During the following days symptoms improved, but ten days later, an MR scan showed a focus of cerebritis and a left parietal abscess (Fig. 4-A)

After ten days ceftriaxone was stopped and a therapy based on linezolid plus levofloxacin continued for 4 weeks more. The following brain MR scan showed a decrease in size of the parietal left lesion (Fig. 4-B). Therapy was well tolerated and continued for further 4 weeks until the abscess was completely resolved, without residual lesions (Fig. 4-C). Patient 5. A 59 year-old man come to our attention for headache, fever, ataxia, vertical diplopia, left Horner syndrome. He had dental care few weeks before. He was diagnosed with an abscess in the medulla ob/ungata at a brain CT scan. Oral levofloxacin and linezolid because of the absence of microbiological findings at the lumbar puncture. The brain MR confirmed a bulbar abscess of $1,6 \mathrm{~cm}$ in diameter, localized in the left side, and surrounding edema (Fig. 5-A, 5-B). During the first month of antibiotic therapy his clinical conditions improved significantly with progressive resolution of symptoms. A brain MR performed three month later, showed a residual focal area of contrast enhancement, which remain stable on the following scans (Fig. 5-C). Patient 6. An 83 year-old woman, came to our ward because of nausea, vomiting, fever $\left(\mathrm{T} 38^{\circ} \mathrm{C}\right)$, headache, ophthalmoplegia and loss of consciousness. A lumbar puncture was performed with a normal biochemical findings and without any microbiological findings. Blood cultures were negative too.

At the brain MR were found 3 little lesions of the brainstem, between the medulla oblungata and the pons (Fig. 6-A, 6-B). Oral antibiotic therapy with levoxacin and linezolid was started, the patient was temporarily lost at follow-up because of femur fracture. Nevertheless she had a complete resolution of the lesion documented at MR five months later (Fig. 6-C). Patient 7. A 87 year old woman, presented fever (39 ${ }^{\circ} \mathrm{C}$ ), left earache with hearing loss and speech disorder. At the CT scan there was a flogistic opacification of the middle ear. She had a paraganglioma and a $4 \mathrm{~mm}$ dehiscence of the tegmen tympani. The lesion developed within few days into an abscess ( $\varnothing 2,4 \mathrm{~cm})$ of the left temporal lobe. Microbiological samples were completely negative and no neurosurgical procedure was performed. The patient started levofloxacin and linezolid. Because of haematotoxicity, linezolid was stopped after one month. Levofloxacin was continued for one month more. She recovered completely in the first two weeks after starting therapy, except for the hearing loss. The brain CT scan performed at the end of the therapy documented the resolution of the lesion (Fig. 7). Patient 8. A 59 year-old man reporting a single episode of paresthesia affecting the right arm, forearm and hemiface lasting 30 minutes. A brain MR evidenced an intra-axial focal lesion of $25 \mathrm{~mm}$ in diameter with peripheral contrast enhancement (Fig. 8-A). Blood cultures and echocardiography were negative and he was started on antiedema and antibiotic treatment with oral levofloxacin and i.v. linezolid with improvement of the neurological symptoms. After two weeks linezolid was shifted to oral regimen as well and the patient was discharged. When the steroid therapy was stopped an epileptic crisis occurred and the patient showed signs of the Achilles tendon inflammation, so levofloxacin was stopped and steroid reintroduced along with levetiracetam. After almost two months of therapy a neuroradiological improvement was documented and linezolid was stopped (Fig. 8-B). The patient continued on steroid and antiepileptic treatment for additional two months. A long-term follow up (after 2 years) MR scan showed residual area of gliosis (Fig. 8-C).

Choice of Antibiotics. Streptococcus, Staphilococcus species, and less commonly Enterobacteriacee, are often the etiologic cause of brain abscess $[5,6,18]$ not related to neurosurgical procedure[8, 9, 10]. Common opinion is that therapy should start as soon possible, after blood and liquor sampling. Empirical treatment should cover all species mentioned above[6]. Oxazolidone derivative linezolid, which has good tissue penetration into CSF trough the blood-brain barrier, has been used in the treatment of CNS gram-positive infections. It has excellent bioavailability through the oral route of administration and no dose modification is needed in case of liver disease or renal failure[7, 16]. It has activity against gram-positive cocci, methicillin-sensitive S. aureus (MSSA), methicillin-resistant S. aureus (MRSA), vancomycin-resistant E. faecium and Streptococcus spp. It is a potential alternative agent against Actinomyces sp, Listeria monocytogenes, Nocardia, and Peptostreptococci.

Levofloxacin has a good oral bioavailability as well, it has favourable pharmacodynamic treating severe infections such as meningitis[7], with good CSF penetration (66\% of standard dose). Levofloxacin is active against Streptococcus, Chlamydia, Legionella, Mycoplasma pneumoniae,

Page $4 / 12$ 
Shigella; moreover it is a potential alternative agent for Enterobacter, Listeria, Leptospira, Proteus, MSSA, Peptostreptococci, Salmonella, Serratia.

For PK-PD profile and spectrum levofloxacin and linezolid can cover almost all the microbiological cause of brain abscess.

Timing of Hospitalization and follow-up. Period of hospitalization was variable, from 6 to 34 days (median of 21,2 days). All patients had followup comprehensive of blood biomarkers, imaging and TDM monitoring. We performed medical visit and blood examination every week during the month following the discharge. After two months all patients had a radiological imaging, repeated at six and 12 months. For all patients, hospital discharge was shorter compared to the period required for traditional intravenous antibiotics for bacterial brain abscess. Decrease of abscess sizes was evaluable since the two first weeks by intracranial RMN or CT scan of the brain[28].

\section{Discussion}

It is known that successful treatment of brain abscesses requires surgery, appropriate antibiotic therapy, and eradication of the primary source[89].

Several studies have evaluated the risk factors for outcome[10]. Tseng retrospectively analyzed the outcomes of 142 patients. The multivariate logistic regression showed some favourable factors: male gender, GCS > 12 and being sepsis-free, similar to study of Xiao et al. The authors found no association between outcome and treatment type[11-12].

Other risk factors influencing mortality and sequelae were: initial neurological grade $(\mathrm{GCS}<12)$, the size of the abscess, meningism, high fever $(>$ $38.5^{\circ} \mathrm{C}$ ), and leukocytosis $(>20.000 / \mathrm{L})^{12}$ [12]. Antimicrobial treatment alone has been proposed in patient with lesion with a diameter less than 2 $\mathrm{cm}$ and for multiple small abscess because of the technical difficulties and the little improvement in outcome after surgery[13].

Surgery is crucial for the correct management and the best outcome[13]. Available procedures are: open evacuation, excision, stereotactic aspiration[14]. These techniques are performed in order to obtain microbiological diagnosis, to enhance the efficacy of antibiotic therapy, to reduce intracranial pressure and avoid the spreading of infection into ventricles[15]. In case of subdural empyema and cerebellar abscess (high risk of herniation), urgent evacuation is mandatory. The choice of the type of surgical approach does not influence the outcome[16].

There is not enough evidence to make specific recommendations for antibacterial treatment and the choice of treatment should be based on culture, clinical data and pharmacokinetic/pharmacodynamic consideration. Published data come from retrospective[17], not randomized trial, from studies not designed to detect differences between diagnostic and surgical techniques or between antimicrobial regimen[18]. They often included long periods of time with great variety in diagnostic methods, microorganism sensitivity and antimicrobial molecules available.

Current management is to start a wide-broad spectrum antibiotic therapy, capable of crossing blood-brain barriers in adequate concentrations. The empiric treatment has to be active on both aerobic and anaerobic pathogens since CNS abscess are polymicrobial in more than one third of cases[19].

Antibiotics with a good penetrations into CNS and successfully administered in various association are penicillin, ampicillin, cefuroxime, chloramphenicol, co-trimoxazole, ceftazidime, and metronidazole, reaching therapeutic concentration[20, 21].

The regimen of choice is therefore a third-generation cephalosporin such as cefotaxime/ceftriaxone/ceftazidime plus metronidazole. In case of history of penetrating trauma or a recent neurosurgical procedure it is necessary to add vancomycin[22].

Various studies have documented that optimal exposure in the CSF with lipophilic agents such as rifampin[23], linezolid[24], levofloxacin [25] and moxifloxacin, may also be achieved with standard dosages even in the presence of undamaged barriers. As regards linezolid, its use in CNS infections is successfully reported in treatment of meningitis and ventriculitis caused by difficult Gram-positive bacteria even in neonate, in cerebral abscesses of other origins where there is even less experience[26, 29].

On the other hand, for hydrophilic antimicrobials such as third-generation cephalosporins, meropenem [30] and vancomycin[31], dosages larger than standard ones may be necessary.

Nevertheless it is important to pursuit an etiological diagnosis in order to allow narrowing the antibiotic spectrum. The sample for microbiological analysis has to be collected before or within 3 days from the start of the antibiotic treatment, afterwards the probability of having positive culture dramatically reduced.

Duration of treatment is not standardized and should be based on etiologic cause, radiologic improvement and response to treatment. At least 4-6 week to 6-8 weeks of treatment is suggested[16]. At least two weeks of intravenous treatment are indicated[16, 18]. Surgical management (drainage) should be considered in case of evidence of growing of the BA or no change in size after 2-3 weeks of therapy, to enhance response to antibiotics. 
At regards adjunctive treatment [32] with steroids, there are no randomized clinical study to strongly recommend their use for reducing BA surrounding edema. Anyway it is recommend perioperatively in order to reduce intracranial pressure avoiding herniation in patients presenting meningitis signs and diffuse cytotoxic edema[33].

Anticonvulsant therapy is started in case of seizures and to prevent further episodes. The Authors do not agree on its duration, which is tailored on each patient according to clinical parameters together with EEG studies in the follow-up phase[33, 34].

There are not enough evidence to establish which patient is eligible for medical treatment, drug of choice for empirical treatment and its shift to "per os" administration. The aim of this article is to propose a new approach for the management of adult, non critical, immunocompetent patients that can undergo an early per os empiric antimicrobial regimen.

\section{Conclusion}

To our knowledge, this is the first case series showing that oral antibiotics for a severe disease such as brain abscess may be a valid alternative to intravenous treatment. For all patients with a good Glasgow Coma Scale, without risk for MDR, shift to oral treatment is feasible, simplifying therapy, reducing the length of hospital stay and costs. Several retrospective analysis concluded that the combination of cefotaxime and metronidazole may be an effective regimen for empiric coverage but experts are asking to review the current empirical antibiotic treatment[35, 36, 37]. Linezolid has better penetration and higher CSF levels compared to vancomycin [28, 31]. It is our opinion that linezolid can be proposed for a first-line empirical treatment in brain abscesses. Adverse hematological effect can be monitored with frequent blood tests. Recent warnings about tendon rupture and aortic dissection during fluoroquinolon treatment[38] may discourage their use. This event is approximately only 1 cases per 10.000 treatment courses and is not linked to lenght.

Suspension of antimicrobial therapy was guided by improvement of clinical conditions and radiological resolution of the lesions[39] and radiologic decrease of abscesses sizes was evident since the second week of oral treatment.

Our clinical experience in the management of oral antibiotic treatment of bacterial brain abscess is comfortable, we think we'll continue to investigate in order to collect strong data to encourage early and safe shift to oral regimen to cure brain abscess in similar clinical scenario.

\section{Declarations}

\section{Funding}

No funding to declare.

The authors state that no fund has received for this paper. This study was carried out as part of our routine work.

This study is retrospective and observational, furthermore it's was approved by competent Ethics Committee,code n. 13/2022/Oss/AOU BO .

\section{Data Availability}

Anonymised data can be obtained from the corresponding author upon request

\section{Trasparency declaration}

The authors declare that they have no competing interests or any financial conflict of interests and they haven't received any assistance of professional medical writer or similar service for preparation of the manuscript.

Author's contributions. All the Authors have seen and approved the manuscript and have contributed significantly to the work.

Consent to participate and for publication: not applicable

\section{References}

1. Matthijs C. Brouwer, M.D. Ph.D, Allan R. Tunkel, M.D., Ph.D., Guy M. McKhann II, M,D., and Diederik van de Beek, M.D., Ph.D. Brain Abscess. N England J Med 2014; 371-56

2. H. K. Li, I. Rombach, R. Zambellas, A.S Walker, M.A. McNally, B.L. Atkins, B.A. Lipsky, H.C Hughes, D. Bose, M. Kumin et al. Oral versus Intravenous Antibiotics for Bone and Joint Infection. N Engl J Med 2019; 380: 425-36

3. Helen W. Boucher, M.D. Partial Oral Therapy for Osteomyielitis and Endocarditis - Is It Time? N Engl J Med 2019; 380;5 : 487-489.

4. Germiller JA, Monin DL, Sparano AM, Tom LW. Intracranial complications of sinusitis in children and adolescents and their outcames. Arch Otolaryngol Head NecK Surg. 2006: 132(9): 969-976 
5. Lu CH, Chang WN, Lin YC, et al. Bacterial brain absecess: microbiological features, epidemiological trends and therapeutic outcomes. QJM.2002;95(8): 501-509.

6. R. Sonneville, R. Ruimy , N. Benzonana , L. Riffaud, A. Carsin , J.-M. Tadi_, C. PM. Revest, P. Tattevin , the ESCMID Study Group for Infectious Diseases of the Brain (ESGIB). An Update on Bacterial Brain Abscess in Immunocompetent Patients. Clinical Microbiology and Infection 23 (2017) 614-620

7. C J Destache, C B Pakiz, C Larsen, H Owens and A K Dash. Cerebrospinal fluid penetration and pharmacokinetics of levofloxacin in an experimental rabbit meningitis model. Journal of Antimicrobial Chemotherapy (2001) 47, 611-615.

8. AR Tunkel. Brain abscess. In : Mandell GL, Bennett JE, Dolin R, eds. Principles and practice of infectious diseases. 7th ed. Philadelphia: Churcill Livingston, 2010: 1265-78

9. H.A. Miranda, S. M. Castellar-Leones, M. A Elzain et al. Brain abscess: Current management. J Neurosci Rural Pract. 2013 Aug; 4(Suppl 1): S67-S81. doi: 10.4103/0976-3147.116472

10. Brower MC, Coutinho JM, van de Beek D Clinical characteristics and outcome of brain abscess: systematic review and meta-analysis. Neurology . 2014 Mar 4; 82 (9): 806-13

11. Xiao F, Tseng MY, Teng LJ, Tseng HM, Tsai JC. Brain abscess: clinical experience and analysis of prognostic factors. SurgNeurol 2005;63:442-50.

12. Tseng JH, Tseng MY. Brain abscess in 142 patients: factors influencing outcome and mortality. SurgNeurol 2006;65:557-62.

13. Hall WA, Truwit CL. The surgical management of infections involving the cerebrum. Neurosurgery. 2008;62(Suppl 2):519-30.

14. Nathoo N, Narotam PK, Nadvi S, Van Dellen JR. Taming an old enemy: A profile of intracranial suppuration. World Neurosurg. 2012;77:48490 .

15. Yang SY. Brain abscess: A review of $\mathbf{4 0 0}$ cases. J Neurosurg. 1981;55:794-9.

16. M. Arlotti , P. Grossi, F. Pea, G. Tomei, Vincenzo Vullo, F. G De Rosa, G. Di Perri, E. Nicastri, F. N Lauria, G. Carosi, M. Moroni, G. Ippolito, GISIG (Gruppo Italiano di Studio sulle Infezioni Gravi) Working Group on Brain Abscesses.Consensus document on controversial issues for the treatment of infections of the central nervous system: bacterial brain abscesses. Int J Infect Dis. 2010 Oct;14 Suppl 4:S79-92. doi: 10.1016/j.ijid.2010.05.010. Epub 2010 Sep 16.

17. S. WU, Y. Wei, X. YU, Y Peng, P He, H Xu, C Qian, G Chen. Retrospective analysis of brain abscess in 183 patients. A 10 -year survay. Medicine 2019; 98:46.

18. Mamelak AN, Mampalm TJ, Obana WG, Rosenblum ML. Improved management of multiple abscesses: a combined surgical and medical approach. Neurosurgery. 1995 Jan; 36 (1): 75-85

19. Muzumdar D, Jhawar S, Goel A. Brain abscess: An overview. Int J Surg. 2011;9:136-44.

20. JanssonAk, Enblad P, Sjolin J. Efficacy and safety of cefotaxime in combination with metronidazole for empirical treatment of brain abscess in clinical practice: a retrospective study of 66 consecutive cases.Eur J ClinMicrobiol Infect Dis . 2004; 23(1):7-14.

21. Infection in Neurosurgery Working Party of the British Society for Antimicrobial Chemotherapy. The rational use of antibiotics in the treatment of brain abscess. Br J Neurosurg. 2000;14:525-30.

22. Mace SE. Central nervous system infections as a cause of an altered mental status? What is the Pathogen growing in your central Nervous system?Emerg Med Clin North Am. 2010;28:535-70.

23. Nau R, Prange HW, Menck S, Kolenda H, Visser K, Seydel JK. Penetration of rifampin into the cerebrospinal fluid of adults with uninflamed meninges. J AntimicrobChemother 1992;29:719-24.

24. Myriathes P, Markantonis SL, Vlachos K, Anagnostaki M, Boutzouka, Panidis D, Baltopoulos G Serum and Cerobrospinal Fluid Concentrations of Linezolid in Neurosurgical Patients.Antimicrob Agents Chemother 2006; 50: 3971-3976

25. Pea F, Pavan F, Nascimben E, Benetton C, Scotton PG, Vaglia A, et al. Levofloxacin disposition in cerebrospinal fluid in patients with external ventriculostomy.Antimicrob Agents Chemother 2003;47:3104-8.

26. Manfredi R, Sabbatani S, Marinacci G, Salizzoni E, Chiodo F. Listeria monocytogenes meningitis and brain abscesses in an immunocompetent host. Favorable response to combination linezolid-meropenem treatment. J Chemother 2006;18:331-3.

27. Leiti O, Gross JW, Tuazon CU. Treatment of brain abscess caused by Listeria monocytogenes in a patient with allergy to penicillin and trimethoprim-sulfamethoxazole. Clin Infect Dis 2005;40:206-7.

28. Boak LM, Li J, Spelman D, Du Cross P, Nation RL, Rayner CR. Successful treatment and cerebrospinal fluid penetration of oral linezolid in a patient with coagulase negative Staphylococcus ventriculitis. Ann Pharmacother 2006;40:151-5.

29. Kumar S, Kholhoff S, Valencia G, Hammerschlag MR. Treatment of vancomycin resistant Enterococcus faecium ventriculitis in a neonate.Int $J$ Antimicrob Agents 2007;29:740.

30. Nau R, Lassek C, Kinzig-Schippers M, Thiel A, Hilmar P, So“” rgel F. Disposition and elimination of meropenem in cerebrospinal fluid of hydrocephalic patients with external ventriculostomy. Antimicrob Agents Chemother 1998;42:2012-6. 
31. Albanese J, Leone M, Bruguerolle B, Ayem ML, Lacarelle B, Martin C. Cerebrospinal fluid penetration and pharmacokinetics of vancomycin administered by continuous infusion to mechanically ventilated patients in an intensive care unit. Antimicrob Agents Chemother 2000;44:1356-8.

32. Obana WG, Rosemblum ML. Nonoperative treatment of neurosurgical infections. NeurosurgClin N Am. 1992 Apr; 3(2): 359-73.

33. Lee TH, Chang WN, Su TM, Chang HW, Lui CC, Ho JT, et al. Clinical features and predictive factors of intraventricular rupture in patients who have bacterial brain abscesses. J NeurolNeurosurg Psychiatry. 2007;78:303-9

34. Garibi JM. Prophylactic antiepileptic treatment of cerebral aggressions. Rev Neurol. 2002;34:446-8.

35. Sáez-Llorens X. Brain abscess in children. SeminPediatr Infect Dis. 2003;14:108-14.

36. Lu CH, Chang WN, Lui CC. Strategies for the management of bacterial brain abscess. J ClinNeurosci. 2006;13:979-85.

37. Leone S, Migliorino G. Brain Abscess. Correspondence. N EnglJMed 2014; 371:1756-1758.

38. Björn Pasternak, MalinInghammar, Henrik Svanström. Fluoroquinolone use and risk of aortic aneurysm and dissection: nationwide cohort study. BMJ 2018; 360 doi: https://doi.org/10.1136/bmj.k678

39. Nathoo N, Nadvdi SS, Narotam PK, van Dellen JR. Brain Abscess: management and outcame analysis of computed tomography era experience with 973 patients. World Neurosurg. 2011; 75(5-6): 716-726.

\section{Figures}

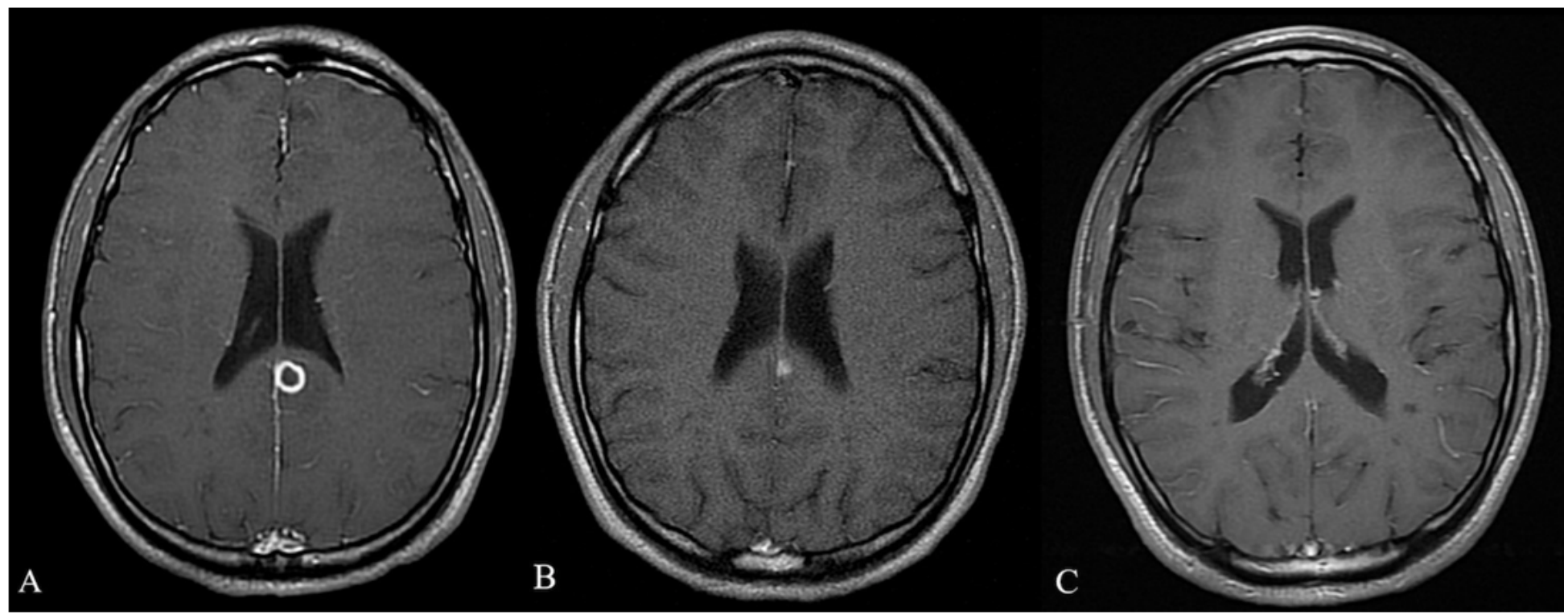

Figure 1

Left posterior cingulate abscess rim enhancement at post-contrast T1w images (A); abscess shrinkage after 2 weeks of treatment with oral antibiotics(B); complete resolution after 2 months (C). 


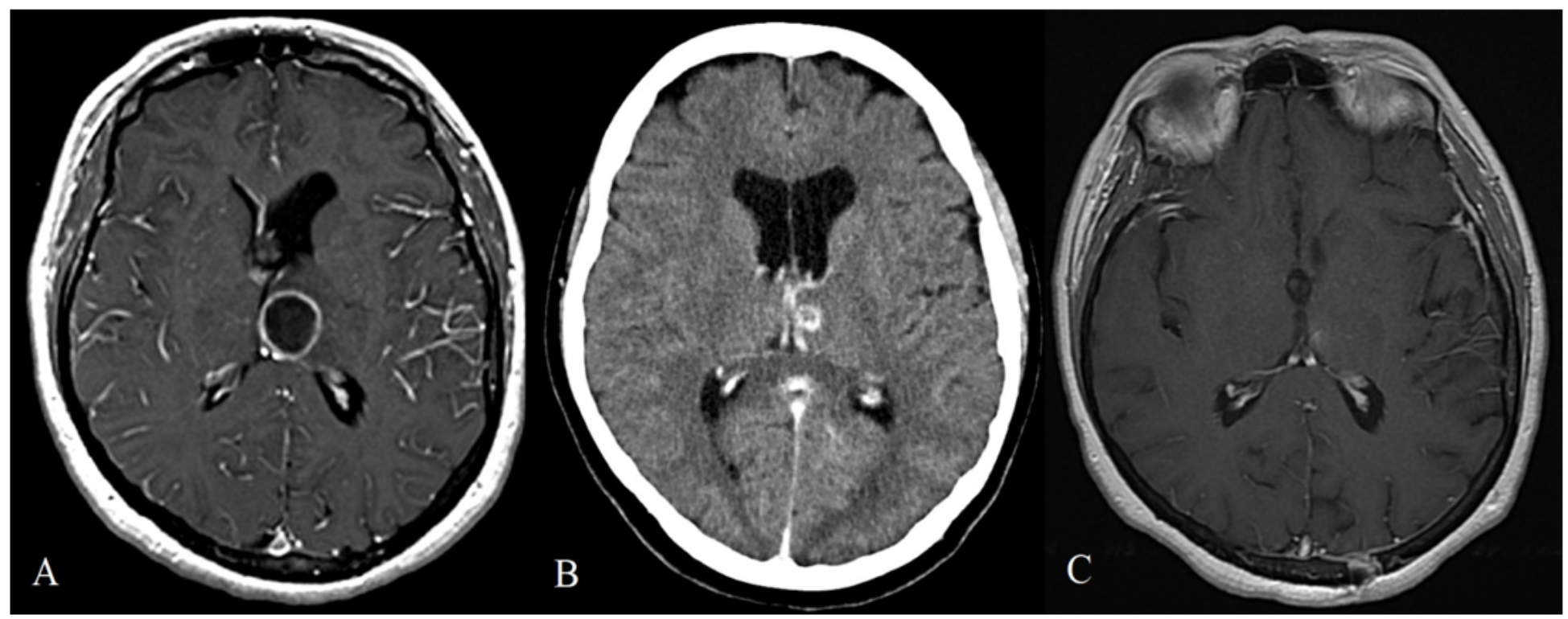

Figure 2

Left thalamic abscess with rim enhancement on contrast-enhanced MR (A); decreased size of the abscess after 2 weeks of treatment with oral antibiotics (B). MR follow up after 1 month (C) shows very subtle residual enhancement in the left thalamus due to persistent BEE breakdown.

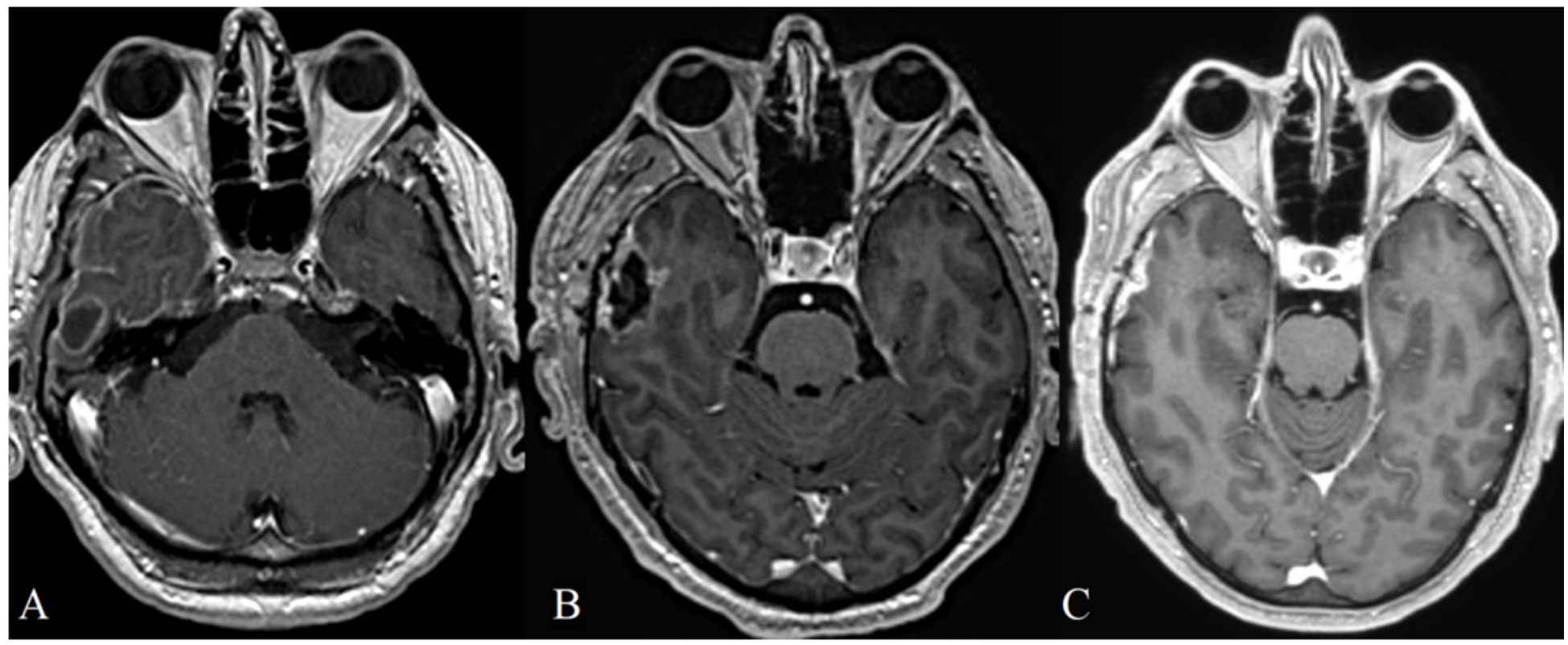

Figure 3

Contrast-enhanced MR images show a right temporal abscess with rim enhancement $(A)$. MR images after surgical drainage shows resolution of the abscess (B) but the persistence of a post-surgical subdural fluid collection. An MR performed after two months show complete normalization of the imaging, except for a residual dural thickening $(\mathrm{C})$. 


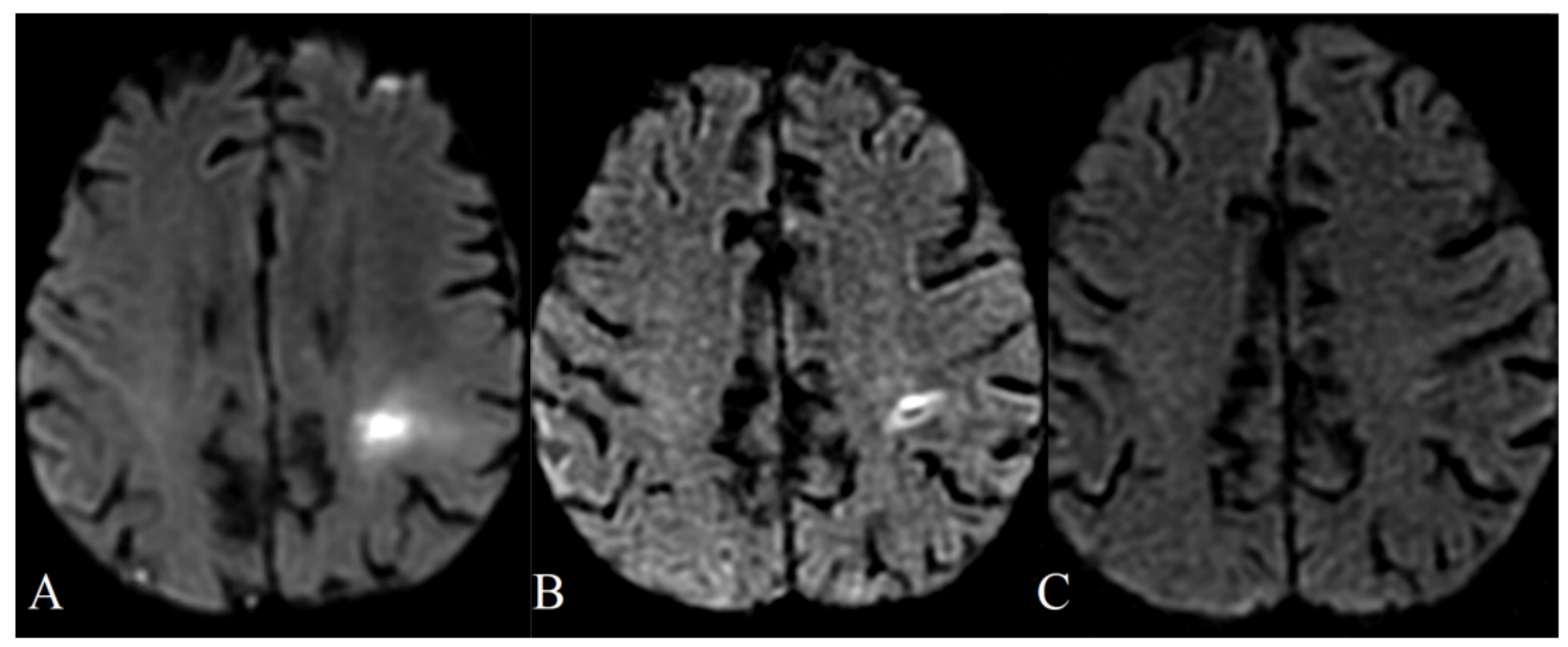

Figure 4

MR scan show an area of restricted diffusion on DWI imaging (A) consistent with a focus of cerebritis/early abscess. Follow up MR images 2 months later show a reduction of area of restricted diffusion on DWI imaging (B). A resolution of the infection with the normalization of DWI imaging (C) seen at an MR performed 6 months after the end of treatment.

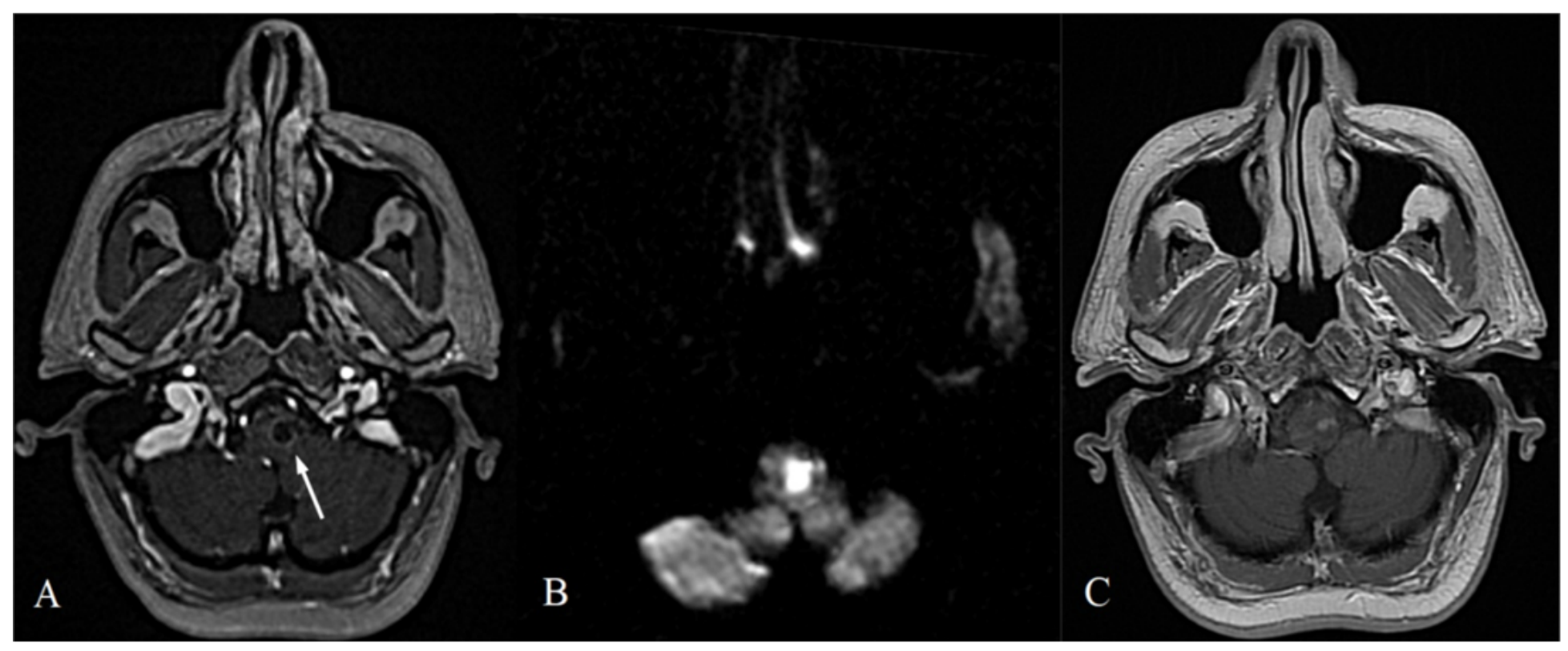

\section{Figure 5}

Contrast - enhanced MR images show a bulbar abscess on the left side with a rim enhancement (white arrow, A) and a corresponding area of restricted diffusion (B); 2 months follow up after treatment with oral antibiotics: a focal residual area of enhancement on the left medulla oblungata (C) and resolution of diffusion restriction (not shown). 


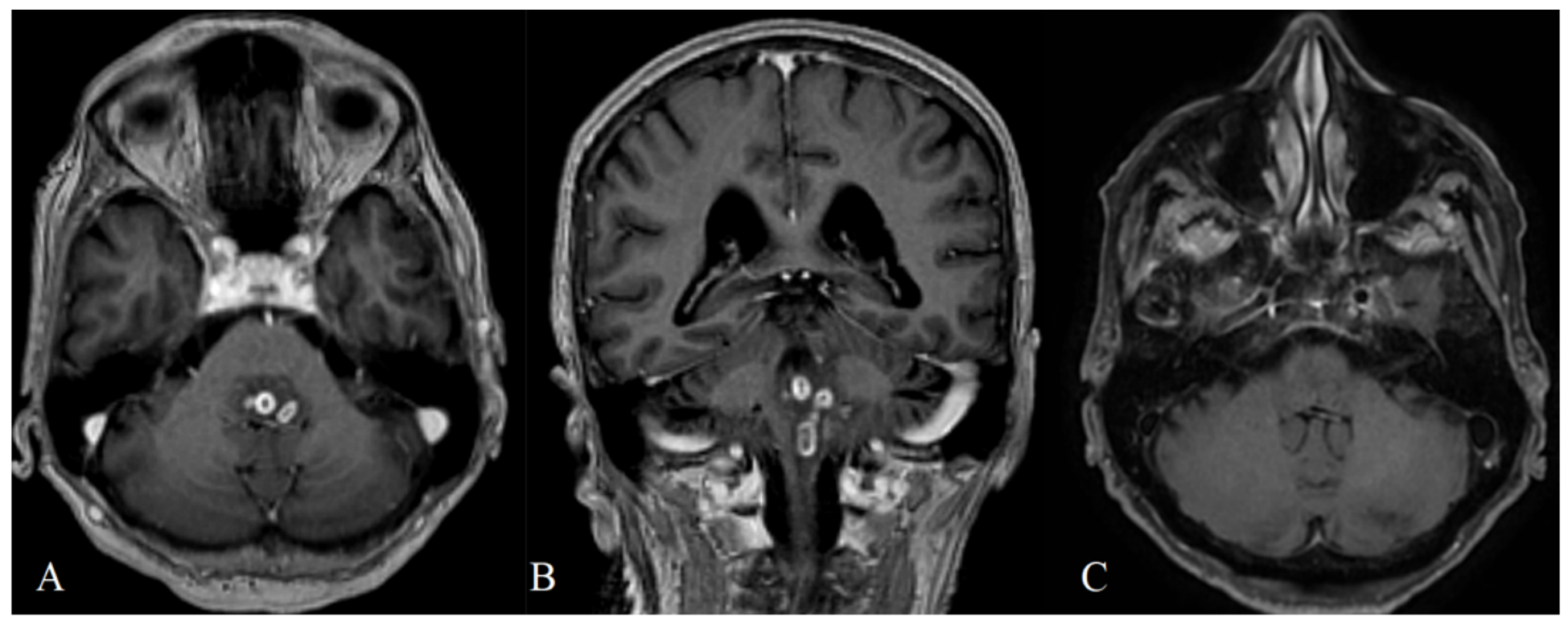

Figure 6

Contrast - enhanced MR images show multiple focal lesions with rim enhancement compatible with abscesses in the dorsal pons and medulla oblungata (A, B). After therapy with oral antibiotics, follow up imaging at 5 month shows complete resolution of the lesions (C).

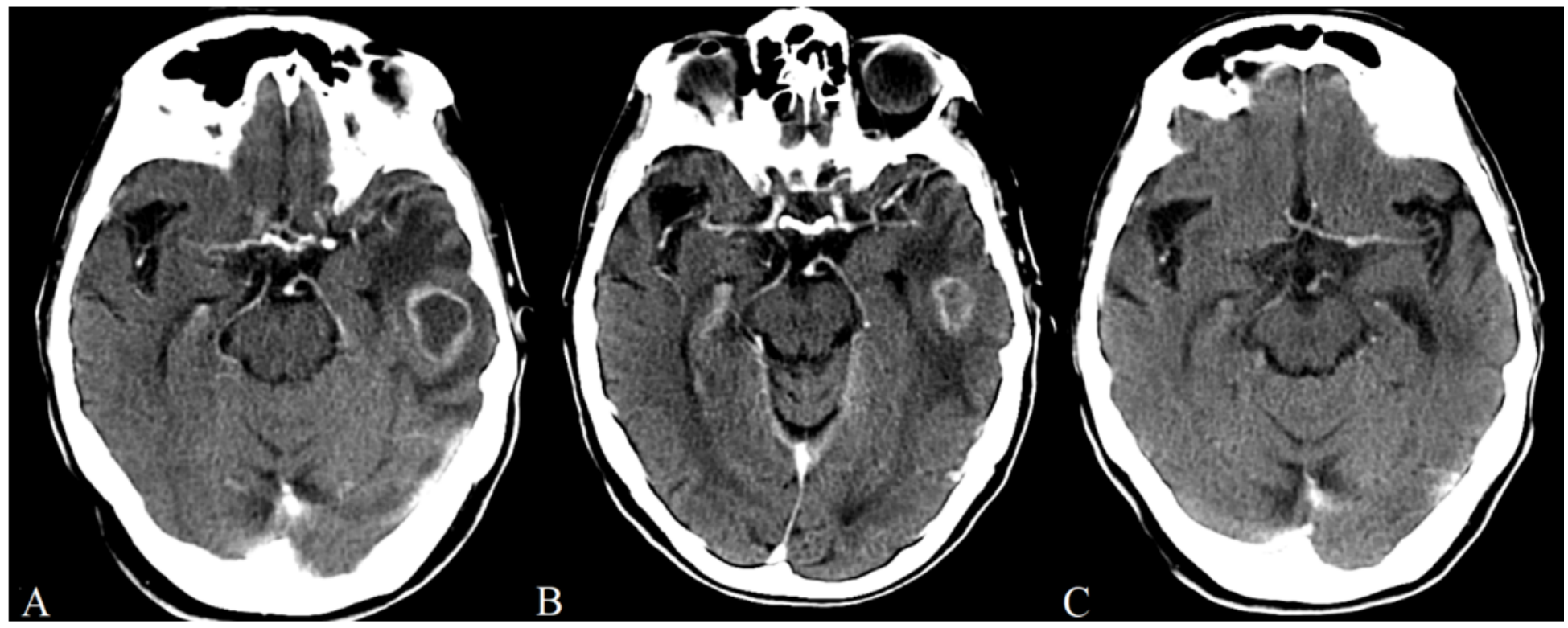

Figure 7

Contrast-enhanced CT reveal left temporal abscess with rim enhancement and perilesional edema (A); decreased size of the abscess after 2 weeks of treatment with oral antibiotics (B); complete resolution of the abscess with residual area of parenchymal hypodensity due to malacic changes (C) at 1 month follow up. 


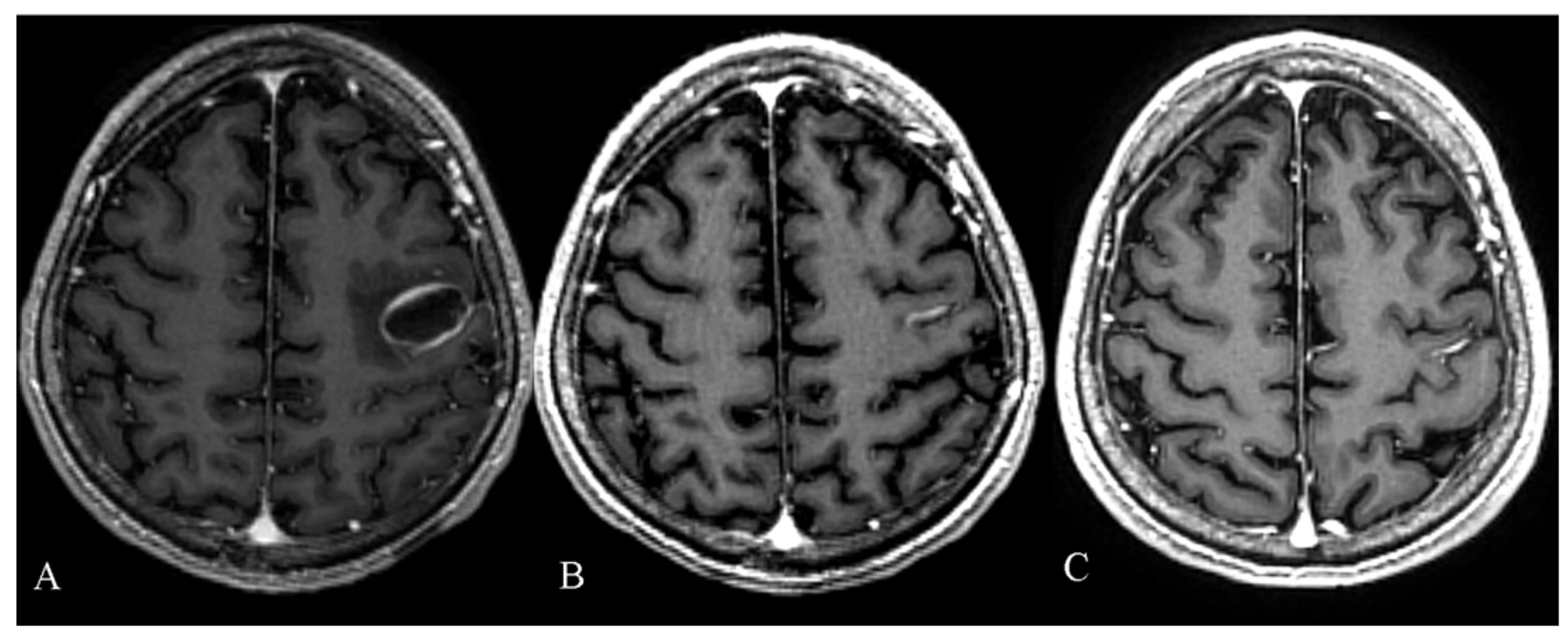

Figure 8

Contrast-enhanced MR revealed a left frontal abscess with rim enhancement (A); an MR scan after two months show a resolution of the abscess (B) with a residual area of gliosis which remain stable over the 2 years (C).

\section{Supplementary Files}

This is a list of supplementary files associated with this preprint. Click to download.

- checklistitemdescription.pdf 